\title{
Cancer and productivity loss in the Irish economy: an employer's perspective
}

Research Article

\author{
Paul Hanly ${ }^{1 *}$, Alison Pearce ${ }^{2}$ and Linda Sharp ${ }^{3}$ \\ 'National College of Ireland, Ireland \\ ${ }^{2}$ National Cancer Registry Ireland, Ireland \\ 3Institute of Health \& Society, Newcastle University, United Kingdom
}

\begin{abstract}
The extant literature suggests that cancer-related premature mortality costs have increased over time and are projected to increase further. Previous studies have generally employed a societal rather than an employer-based costing framework. A question therefore remains over the magnitude of productivity costs associated with premature death from cancer from an employer perspective. The objective of this study was to measure the productivity costs associated with cancer-related premature mortality in Ireland using the employer-focussed friction-cost approach (FCA). This entailed the application of an involuntary turnover costing framework rarely used in the management literature and represents the first estimate of its kind in Ireland. The all-cancer premature mortality cost was valued at $€ 14.3$ million in 2009. We modelled the sensitivity of our costs to changes in underlying labour market conditions and to 'multiplier effects' which represent recent advances in the FCA. We advocate that future studies should concentrate on combining elements of direct turnover cost according to accounting costing frameworks with the indirect costs measured by the FCA. Implications for current guidelines for the economic evaluation of health technologies in Ireland are also discussed.
\end{abstract}

Keywords: cancer; employer perspective; friction-cost approach; premature mortality; productivity costs

(C) De Gruyter Open Sp. z 0.0 .

\section{INTRODUCTION}

Cancer is a leading cause of death internationally and is the second leading cause of death in Ireland after cardiovascular diseases, a pattern commonly seen in developed countries (WHO, 2008). Specifically, in Ireland cancer deaths represented $30 \%$ of all deaths in 2010 amounting to an average of over 8,000 deaths annually (NCRI, 2013a). The consequences of cancer-related mortality are tragic on a personal level for those affected, but beyond this there are also implications for public health, the economy and society in general. This study focuses on one aspect of cancer, namely the costs this disease impose on employees and employers from an economic perspective (Hanley and Sharp, 2012; Oliva et al., 2005).

When an employed individual is diagnosed with cancer, a short- or long-term absence from work normally ensues due to treatment, related side effects or rehabilitation (Bradley et al., 2006; Mehnert, 2011; Mehnert et al., 2013; Sharp and Timmons, 2011). A proportion of patients with cancer also leave the workforce permanently either due to retirement or death. It is the latter of these - specifically cancer-related premature mortality - that constitutes the focus of this study. Premature mortality results in firm turnover which, in turn, constitute direct and indirect economic losses to the employer. The former arise because of the need to fund such things as separation, replacement and training (Tziner and Birati, 1996) and the latter from lost productivity itself. Specifically, the investment that the employer made in the employee is lost if they leave the workforce due to cancer, and this creates a quantifiable cost.

A number of distinct models exist for calculating the costs of turnover in the workforce (Cascio, 1991; Karsan, 2007; Tziner and Birati, 1996); however, these tend to follow general accounting approaches rather than applying economic costing techniques. Where economic costing techniques have been applied, the majority of studies have adopted the human capital approach ( $\mathrm{HCA})$ to productivity cost estimation, which measures potential output lost due to absenteeism and turnover rather than actual output loss. More recent conceptual developments have 
resulted in the development of the friction-cost approach (FCA), which has been claimed as a more meaningful measure of productivity losses from the employer's perspective (Koopmanschap et al., 1995) because it measures the actual output loss following temporary absence or permanent removal of a worker up to the point where the initial firm output level is restored; these two approaches are described in more detail below.

The extant literature suggests that cancer-related premature mortality costs are significant, have increased over time and are projected to increase further (Hanly et al., 2014). For example, in Europe, all cancer sites combined generated a total of $€ 75$ billion in premature mortality costs in 2008 (Hanly et al., 2015). In addition, in the US, total cancer premature mortality costs were forecasted to increase by $27 \%$ from $\$ 116$ billion in 2000 to $\$ 147$ billion in 2020 (Bradley et al., 2008). However, both these studies used the HCA. In fact, very few studies have attempted to estimate cancer-related productivity losses using the FCA and, of those which have been reported, none have estimated costs for a range of cancer sites (Hanly et al., 2014). This is an especially important gap in the literature in the current economic climate; it has been argued that the FCA becomes particularly applicable during periods of less than full employment (Koopmanschap and Rutten, 1996). Consequently, a question remains over the magnitude of the actual productivity costs associated with premature death from cancer from an employer's perspective. The lack of FCA-based estimates of productivity costs are also important in light of the fact that economic evaluations are increasingly used to inform decisions on the introduction of new health technologies internationally; although many of the economic evaluation guidelines incorporate productivity costs (Knies et al., 2010), there is no consensus within these guidelines as to what costing perspective should be adopted.

We aimed to use the FCA to measure cancer-related premature mortality costs in Ireland. Our study entailed the application of a conceptualisation of involuntary turnover costs rarely used in the management literature (FCA) and represents the first estimate of productivity costs associated with cancer-related premature mortality across multiple sites from an employer's perspective in Ireland. As the only study to have applied the FCA to estimate costs for multiple (more than two) cancer sites, it also constitutes an important contribution to the international evidence-base. Moreover, we incorporated recent advances in the methodology underpinning FCA - which have only been previously applied in the Netherlands (Krol et al., 2012) and the US (Nicholson et al., 2006) to model the sensitivity of our costs to 'multiplier effects', which arise from modern working practices. This includes accounting for the additional effects of turnover on team-based work, time-sensitive demand and replacement workers, and the incorporation of which constitute an important contribution to the management literature. Finally, we modelled the effect of changing labour market conditions on our estimates including rising unemployment levels in Ireland. The study thus purports to estimate a more complete value for the lost productivity associated with involuntary turnover and provide a more meaningful measure of lost productivity than traditional turnover frameworks.

\section{INVOLUNTARY EMPLOYEE TURNOVER COSTS: FROM THEORY TO PRACTICE}

Although a considerable breadth of literature exists on the issue of employee turnover, with a recent review (Steel and Lounsbury, 2009) counting 24 distinct turnover models in print, the majority of this concentrates on voluntary turnover, which is defined as the movement across the membership boundary of an organisation initiated by the employee (Price, 1977). Previous studies, including the seminal work by March and Simon (1958), have examined the employee decision to quit based on perceived ease and desirability movement. Refinements of this model included a base turnover model, which extended the knowledge of the withdrawal process (Mobley, 1977; Mobley et al., 1978, 1979), in addition to more recent turnover models informed by developments in decision theory and which incorporate human decision making as a non-linear process (Lee and Mitchell, 1994; Steel, 2002).

Involuntary turnover, in contrast, can be defined as the movement across the membership boundary of an organisation, which is not initiated by the employee (Price, 1977). It is this involuntary turnover, and in particular that linked to deaths (rather than dismissals and retrenchments as defined by Campion (1991)), which comprises the focus of the current study. Our specific focus is on 'premature' deaths due to disease/illness, in this instance cancer. 'Premature' mortality is defined here as death that occurs prior to an individual's retirement from paid employment, although it may be defined in other ways (such as deaths before average life expectancy).

Following the publication of conceptual frameworks on employee turnover (summarised above), a number of studies attempted to examine the financial effects of turnover from the employer's perspective (Cascio, 1991; Karsan, 2007; Tziner and Birati, 1996). These works traditionally involve the use of general accounting approaches to produce an estimate of the costs of turnover to the employer. These estimates may incorporate a range of potential 
direct costs comprising separation costs, including the costs of an exit interview, administration of employee removal and severance pay; replacement costs including advertising a position, processing applications, interviews and orientation activities; and training costs, including disseminating organisational information on regulation, conduct, performance and socialisation, in addition to formal training programmes (Cascio, 1991).

Although there are clearly many forms of direct costs, the indirect costs associated with employee turnover (such as the lost production to the firm following the premature death of the employee) can dwarf these costs. Indirect costs, it may be argued, are more aptly captured through the use of economic costing techniques (although some interesting attempts to quantify these have been made using more traditional accounting practices (Cascio, 1991; Tziner and Birati, 1996)). The economic costing approach attempts to go beyond the traditional financial cost of turnover in measuring the indirect costs of turnover for employers, and (depending on the methodology adopted) for the economy, or society, in general.

In economic costing studies, measurement of disease-related indirect costs was originally undertaken according to the HCA. The HCA adopts a societal, or welfare-based, perspective and attempts to measure the potential stream of output that could have been produced over the course of a lifetime without premature death (in this case, due to cancer). This method values productivity loss as the present value of foregone future income, with lost income acting as a proxy for lost output (Berger et al., 2001; Tarricone, 2006). In a number of seminal studies, Rice (1966, 1967) calculated disease-related morbidity and mortality costs by assessing illness burden in terms of the flow of goods and services foregone in the US. Further development of this conceptual approach was undertaken by Mushkin (1962) who used the HCA in the health care field to evaluate the potential for economic growth. However, some authors (Drummond, 1992; Koopmanschap et al., 1995) have argued that the actual productivity loss in an economy is much smaller than this when a reserve pool of labour - i.e. unemployed people - exists.

A major conceptual development was initiated in the 1990s with the introduction of the friction-cost approach to productivity cost estimation (Koopmanschap et al., 1995). This alternative employer-based perspective values productivity loss over the time span that firms require to restore the initial production level following the loss of a worker (Koopmanschap et al., 1995) and can measure the costs of both temporary work absences and more permanent absences such as those due to premature mortality. It is assumed that, following a premature death of a worker, she/he is replaced by an unemployed individual, either directly or at the end of a chain of vacancies; this replacement incurs zero opportunity cost. The time period necessary to re-establish the original production level is referred to as the 'friction period' and can vary depending on extant labour market conditions. Generally, the higher the level of unemployment in an economy, the shorter the friction period because more potential workers with the requisite skill set are available to replace workers lost due to premature death. Unlike the HCA, the FCA also incorporates the cost for hiring and training new workers, although this is measured in an indirect manner through time costs; additional direct costs are not captured.

Some authors argue that the wage rate represents a lower bound for productivity costs in that it does not take into account: (i) the team-dependent nature of the modern work environment which means that the loss of one team member may inhibit the productivity of the entire team; (ii) the difficulty in finding a perfect substitute replacement worker which may entail comprehensive training until the appointee is as productive as the lost worker and (iii) the fact that a proportion of current firm-level demand is highly time sensitive and the loss of a worker may inhibit the timely supply of the necessary goods or services (Nicholson et al., 2006; Pauly et al., 2002). These arguments have been echoed in the managerial literature which also notes the additional effects of turnover on morale and the cost of maintaining a 'bench' - a group of people available to cover the work of a terminated employee until the new hire is fully ready (Curtis and Wright, 2001; Karsan, 2007; Tziner and Birati, 1996). More recent discussion has focused on the consequences of grief in the workplace following the loss of a colleague, and the productivity costs associated with this (Hazen, 2008, 2009; James and Friedman, 2003). In particular, these additional costs would include the potential impact on colleagues' productivity due to the loss, through a cancer death, of an individual in the workgroup. These costs could be in excess of the pure productivity loss arising from the loss of a team member and relate to the additional effects of grief in the workplace. Recent conceptual developments in the FCA have involved adjustment of the wage rate for a limited number of such so-called multiplier effects (Nicholson et al., 2006; Pauly et al., 2002), but few studies have so far investigated the impact on productivity costs of incorporating these effects.

In light of these conceptual and methodological advances in productivity cost estimation from an economic perspective in recent years, it is now apt to apply the most up-to-date conceptualisation of productivity costs to cancer in Ireland. Given the dependence of the FCA on underlying economic conditions (Koopmanschap and Rutten, 1996), Ireland provides an interesting case study for the application of the methodology. For example, unemployment - which 
is a key driver of the friction period - increased from $4.7 \%$ in 2007 to $13.1 \%$ in 2013 (Statbank, 2014a). In this study, we model the effects of these increased unemployment levels on productivity costs while also being the first to apply the 'multiplier effects' to Ireland. In the discussion, we compare the FCA with other economic and financial costing frameworks to explore a key weakness in the current conceptualisation of the FCA from a management perspective and possible future enhancements to the approach. Finally, we consider what the results mean for the debate on the appropriate perspective and therefore costing approach to employ within economic evaluations.

\section{METHODS}

Our study addresses four research questions: (1) what is the magnitude of productivity costs associated with cancer-related premature mortality in Ireland in 2009 (the base-case year) according to the FCA; (2) to what extent do changing labour market dynamics and the multiplier effects of job turnover impact on FCA productivity cost estimates; (3) how does the FCA productivity cost compare to other economic and financial estimates of premature mortality and (4) what conceptual and methodological refinements are required in the FCA, if any, to provide a meaningful managerial assessment of turnover costs due to premature death.

The conceptual framework underpinning the FCA comprises four core components which aggregate together to produce productivity cost estimate. The first component is the length of the friction period. The second component is the time lost from work due to illness, which is straight forward in the case of premature mortality. In this study, premature mortality is defined as deaths due to cancer which occurred before 65 . Conceptually, the FCA can incorporate any type of workforce absence including temporary and permanent disability; but absences other than those due to premature death are beyond the scope of the current study. The third component is an estimate of the wage rate, which acts as a proxy for lost productivity and is used to cost the time estimates. Finally, the fourth component is an estimate of proportion of reduction in effective labour time resulting from a work absence which might be $<1$ because of, for example, a firm's internal labour reserves (Hanly et al., 2012). A fifth - optional - component is an estimate for 'multiplier effects', which are considered through sensitivity analyses in the current study.

\section{Data sources}

Cancer data: We abstracted data on the average annual number of cancer deaths between the ages of 15 and 64 in Ireland during 2005-2009 by 5-year age group and sex from the World Health Organization (WHO) Cancer Mortality Database (WHO, 2013). We considered all cancers combined (International Classification of Diseases (ICD 10 00-97, B21)) and the 10 cancer sites in males and females for which there were most deaths in people of all ages. These were oesophagus (ICD10 15, males and females); stomach (C16, males and females); colorectal (C18-21, males and females); pancreas (C25, males and females); lung (C33-34, males and females); breast (C50, females); uterus (C53-55, females); ovary (C56, females); prostate (C61, males); bladder (C67, males); brain and central nervous system (CNS, C70-72, males and females); non-Hodgkin's lymphoma (C82-85, C96, males and females) and leukaemia (C91-95, males and females).

Labour market data: We extracted job vacancy duration data from a Central Statistics Office (CSO) survey of 'Employee Skills, Training and Job Vacancies' (CSO, 2009). From this, we derived a friction period of 11.3 weeks, composed of the average job vacancy duration in 2006 (7.3 weeks - the closest year to the base year for which an estimate was available - plus an additional 4 weeks to account for the time required to advertise a job, recruit a replacement worker and provide initial training (Hanly et al., 2012; Tan et al., 2012)). After this period, a firm's initial production level is assumed to be restored. This estimate was used in the base-case analysis. Other base-case valuation data included age- and gender-specific gross annual wages (including bonuses and benefits-in-kind), which came from the National Employment Survey 2009 (Statbank, 2014b), and age- and sex-specific unemployment and labour force participation rates, which were derived from the Quarterly National Household Survey (Statbank, 2014a). Wages were used as a proxy for output loss, as assumed elsewhere in the literature (Tarricone, 2006).

\section{Estimation methods}

In order to estimate the cost of cancer-related premature mortality for Ireland, we first calculated the annual years of potential productive life lost (YPPLL) due to cancer between the ages of 15 (before which it is assumed that workforce participation is negligible) and 64. The upper threshold was based on the pensionable age in Ireland in 2009 and is close to effective male and female retirement ages (64.6 for males and 62.6 for females) between 2009 
and 2012 (OECD, 2013). YPPLL were capped at the base-case friction period of 11.3 weeks, and we then valued these capped YPPLL. In practice, this involved multiplying the friction period (expressed as a fraction of a working year, which was assumed to be 48 weeks) for an individual death by age- and gender-specific annual wages. For example, a female who died from breast cancer between the ages of 45 and 49 had an assumed annual wage of $€ 37,140$ which was multiplied by $11.3 / 48(0.2354)$. We then adjusted for population-level gender-specific labour force participation and unemployment rates. Estimates were subsequently summed over deaths in each 5-year age group to yield age group totals and across age groups to provide totals for all ages. This was done for all cancers combined and each cancer site. Productivity costs were also expressed per cancer death based on the number of deaths in the 15-64 age group. For example, there was an estimated 134.6 (average during 2005-2009) male deaths between 15 and 64 from colorectal cancer with an estimated total cost of $€ 1,182,056$. The cost per cancer death was $€ 1,182,056 / 134$. 6 or $€ 8,782$. All costs were expressed in 2009 euros.

\section{Sensitivity analyses}

Three sensitivity analyses were conducted. First, we accounted for 'multiplier effects' (Nicholson et al., 2006; Pauly et al., 2002) by applying the median multiplier estimate of 1.28 , derived by Nicholson et al. (2006), to our basecase estimates for all cancers combined in males and females. Next, we explored the impact on the all cancers premature mortality cost of the change in unemployment levels between quarter 32006 (when the vacancy period was estimated in the base-case) and 2013 (Statbank, 2014a). Firstly, using adjustment factors derived by ErdoganCiftci and Koopmanschap (2011), we calculated a revised friction period for 2009 of 7.2 weeks and applied this. Secondly, we repeated the analysis using the base-case friction period of 11.3 weeks and 2013 unemployment and labour force participation rates.

\section{RESULTS}

\section{Total deaths by cancer site and gender}

The annual number of cancer deaths in people of all ages in Ireland was 8,067, with males accounting for $53 \%$ of this total (Table 1). The top 10 most common sites in terms of deaths accounted for $76.5 \%$ and $75.4 \%$ of all cancer deaths for males and females, respectively. Lung cancer was the most common cause of death in males (994 deaths per annum; $23 \%$ of the total), followed by colorectal cancer (554 deaths; $13 \%$ ). Breast cancer was the most common cause of cancer-related death in females $(679 ; 18 \%)$ followed closely by lung cancer $(668 ; 18 \%)$ with colorectal cancer a more distant third $(401 ; 11 \%)$.

\section{Total cancer-related premature mortality costs by site and by gender}

In the base-case, total productivity costs due to cancer-related premature mortality amounted to $€ 14.3$ million, $70 \%$ of which was accounted for by premature mortality in males (Table 1). Combining males and females (Figure 1), lung cancer was the most expensive site generating $€ 3.1$ million in productivity costs $(22 \%$ of the total). This was followed by colorectal cancer (€1.5 million; $11 \%$ ) and female breast cancer (1.2 million; $8 \%$ ). In combination, these three cancers accounted for over $40 \%$ of the total cancer-related premature mortality costs.

Male total productivity costs due to premature mortality for all cancer combined were 2.3 times greater than female costs ( $€ 10.0$ million vs. $€ 4.4$ million). The most expensive cancer site in males was lung (total cost $€ 2.5$ million), followed by colorectal cancer ( $€ 1.2$ million) and cancers of the brain and CNS ( $€ 0.7$ million). Breast cancer generated the highest total premature mortality cost for females ( $€ 1.2$ million), followed by lung cancer ( 0.7 million) and cancer of the uterus ( 0.4 million).

\section{Total cancer-related premature mortality costs by age}

All cancer total productivity costs due to premature cancer-related mortality increased with increasing age for both males and females (Figure 2), peaking in the 55-59 age group and falling slightly in those aged 60-64. Male and female productivity costs were similar to age 39 ; thereafter male costs substantially exceeded female costs in all age groups. The difference in costs between the sexes was highest in the 60-64 age group, where male costs were 3.5 times higher than female costs. 
Table 1. Average annual number of deaths (all ages, 2005-2009), total productivity costs due to premature mortality and premature mortality cost per cancer death $(€, 2009)$ for all cancers and the 10 most common cancer sites in males and females in Ireland

\begin{tabular}{|c|c|c|c|c|c|c|}
\hline Cancer site & $\begin{array}{l}\text { Deaths } \\
\text { (\% of the total) }\end{array}$ & Rank & $\begin{array}{l}\text { Total premature mortality } \\
\text { cost ( } \% \text { of the total) }\end{array}$ & Rank & $\begin{array}{l}\text { Premature } \\
\text { mortality cost } \\
\text { per death }\end{array}$ & Rank \\
\hline \multicolumn{7}{|l|}{ Total } \\
\hline All cancers & 8,067 & & $14,328,884$ & & 6,339 & \\
\hline \multicolumn{7}{|l|}{ Males } \\
\hline All cancers & $4,276(100)$ & - & $9,971,386(100)$ & - & 8,709 & - \\
\hline Top 10 cancers & 3,272 (76.5) & - & $7,229,907$ (72.5) & - & 8,776 & - \\
\hline Oesophagus & $218(5.1)$ & 4 & $613,083(6.1)$ & 5 & 8,860 & 4 \\
\hline Stomach & 207 (4.8) & 6 & $488,815(4.9)$ & 6 & 8,920 & 2 \\
\hline Colorectal & $554(13.0)$ & 2 & $1,182,056(11.9)$ & 2 & 8,782 & 6 \\
\hline Pancreas & $217(5.1)$ & 5 & 623,921 (6.3) & 4 & 8,837 & 5 \\
\hline Lung & $994(23.4)$ & 1 & $2,475,876(24.8)$ & 1 & 8,693 & 8 \\
\hline Prostate & $530(12.4)$ & 3 & 327,945 (3.3) & 8 & 8,496 & 10 \\
\hline Bladder & $121(2.8)$ & 10 & $164,105(1.6)$ & 10 & 8,729 & 7 \\
\hline Brain and $\mathrm{CNS}^{\mathrm{a}}$ & $150(3.5)$ & 8 & $675,722(6.8)$ & 3 & 8,891 & 3 \\
\hline $\begin{array}{l}\text { Non-Hodgkin's } \\
\text { lymphoma }\end{array}$ & $132(3.1)$ & 9 & $382,405(3.8)$ & 7 & 9,148 & 1 \\
\hline Leukaemia & $150(3.5)$ & 7 & $295,980(3.0)$ & 9 & 8,554 & 9 \\
\hline \multicolumn{7}{|l|}{ Females } \\
\hline All cancers & $3,791(100)$ & & $4,357,498(100)$ & - & 3,932 & - \\
\hline Top 10 cancers & 2,860 (75.4) & & $3,550,112(81.5)$ & & 3,941 & - \\
\hline Oesophagus & $118(3.1)$ & 8 & $75,983(1.7)$ & 10 & 3,689 & 8 \\
\hline Stomach & $130(3.4)$ & 7 & $114,936(2.6)$ & 8 & 4,105 & 3 \\
\hline Colorectal & 401 (10.6) & 3 & $324,131(7.4)$ & 5 & 3,850 & 5 \\
\hline Pancreas & $218(5.8)$ & 5 & $162,928(3.7)$ & 7 & 3,542 & 10 \\
\hline Lung & 668 (17.6) & 2 & 668,696 (15.3) & 2 & 3,642 & 9 \\
\hline Breast & $679(17.9)$ & 1 & $1,194,773(27.4)$ & 1 & 4,169 & 2 \\
\hline Uterus & $172(4.5)$ & 6 & $359,976(8.3)$ & 3 & 4,337 & 1 \\
\hline Ovary & $254(6.7)$ & 4 & $345,602(7.9)$ & 4 & 3,798 & 7 \\
\hline Brain and CNS & 109 (2.9) & 10 & 201,984 (4.6) & 6 & 3,945 & 4 \\
\hline $\begin{array}{l}\text { Non-Hodgkin's } \\
\text { lymphoma }\end{array}$ & $111(2.9)$ & 9 & $101,102(2.3)$ & 9 & 3,801 & 6 \\
\hline
\end{tabular}

${ }^{a}$ Central nervous system 
Figure 1. Percentage and value of total productivity costs due to premature mortality $(€, 2009)$, by cancer site, for males and females combined

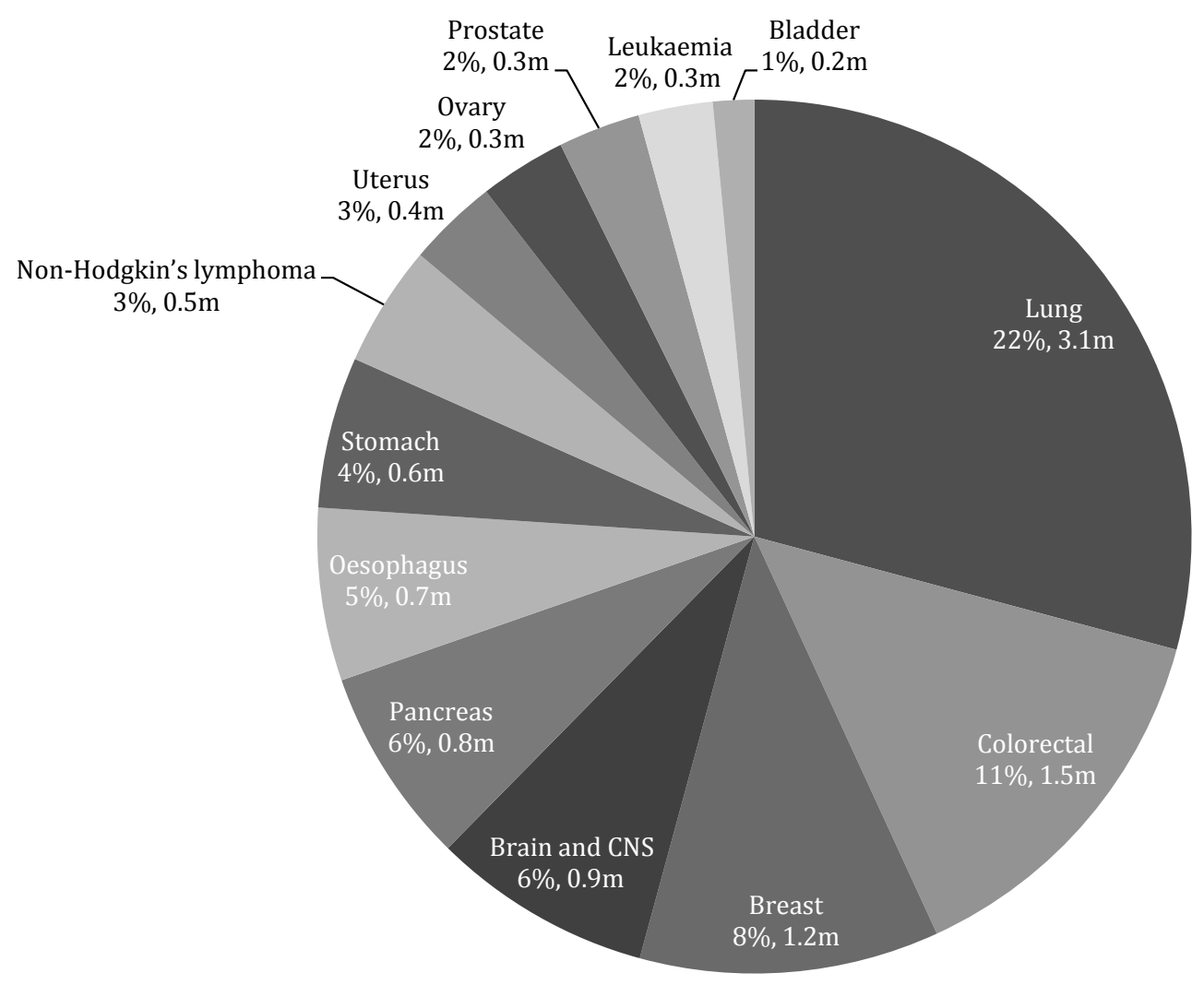

Figure 2. Total productivity costs due to premature mortality $(€, 2009)$, all cancers combined, by sex and age

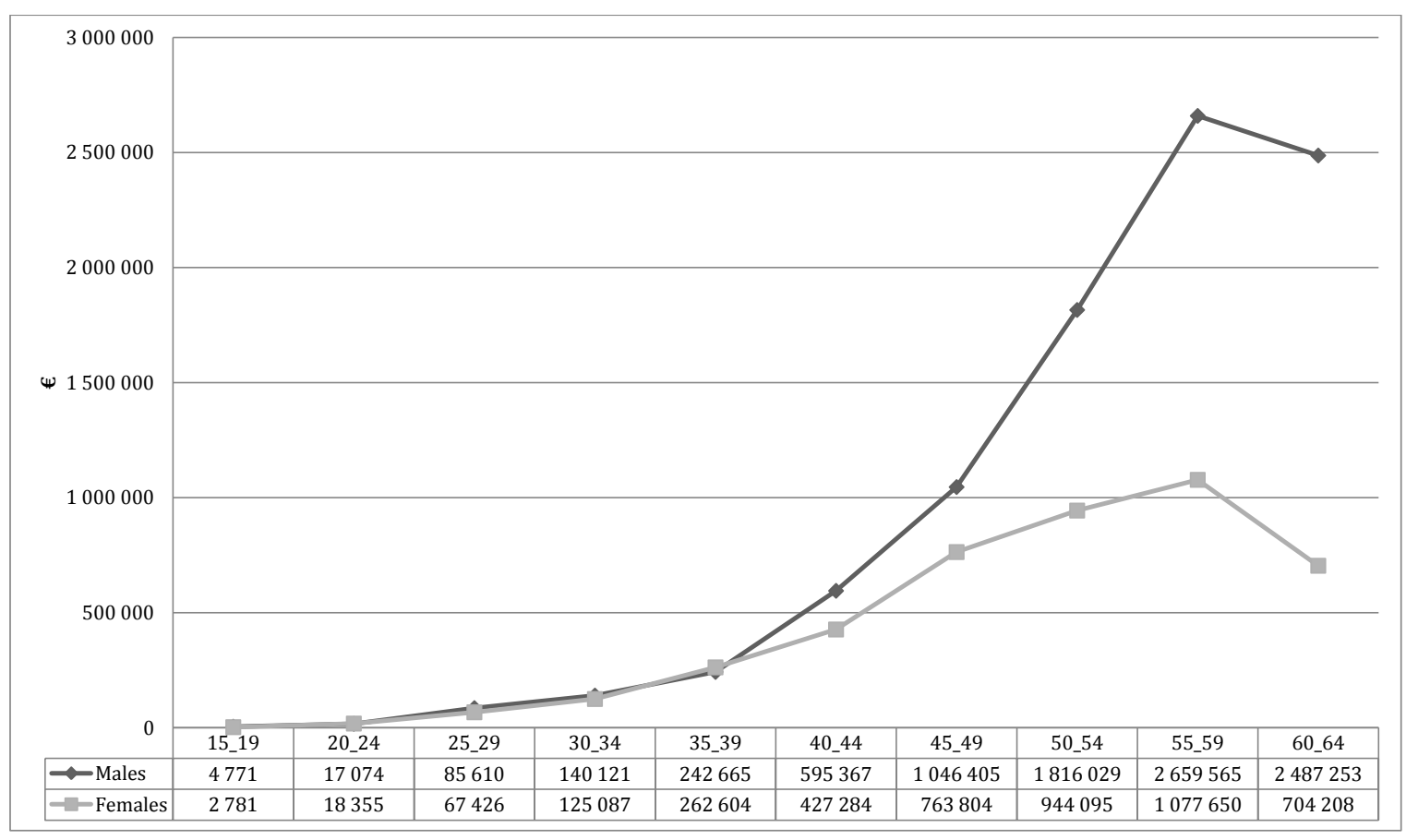




\section{Cancer-related premature mortality cost per death by site and by gender}

When expressed per cancer death, all cancer premature mortality costs in males were more than double those in females (€8,709 per death vs. $€ 3,932$ per death). This pattern was also seen for all sites for which costs were computed for both sexes. The highest premature mortality cost among males was for non-Hodgkin's lymphoma $(€ 9,148$ per death), and the lowest was for prostate $(€ 8,496$ per death); for females the highest cost per death was seen for cancer of the uterus (€4,337 per death) and the lowest for cancer of the pancreas (€3,542 per death).

The ranking of cancers changed considerably when cost per death was considered rather than total productivity costs due to premature mortality. For example, while lung cancer was the most costly cancer site in males in terms of total costs, it ranked $8^{\text {th }}$ according to productivity cost per death. For females, while cancer of the uterus ranked third according to total productivity cost, it was the most costly site according to productivity cost per death.

\section{Sensitivity analyses}

The results of the sensitivity analyses are presented in Figure 3. Accounting for the existence of job-dependent multiplier effects resulted in an increase in all cancer total productivity costs due to premature cancer-related mortality compared to the base-case estimates of $16.7 \%$ in males and $29.1 \%$ in females. Conversely, decreasing the friction period from 11.3 weeks to 7.2 weeks resulted in falls of $41.9 \%$ and $35.8 \%$ in all cancer productivity costs in males and females, respectively, compared to the base-case figures. Finally, the use of 2013 unemployment and participation rates had a modest impact on the all cancer costs in males $(-8.8 \%)$ and almost no impact in females $(+0.8 \%)$.

Figure 3. Sensitivity analysis: total productivity costs due to premature cancer-related mortality (€, 2009) according to different assumptions for the labour market (unemployment rates, participation rates and wage rate multipliers), all cancers combined, by sex

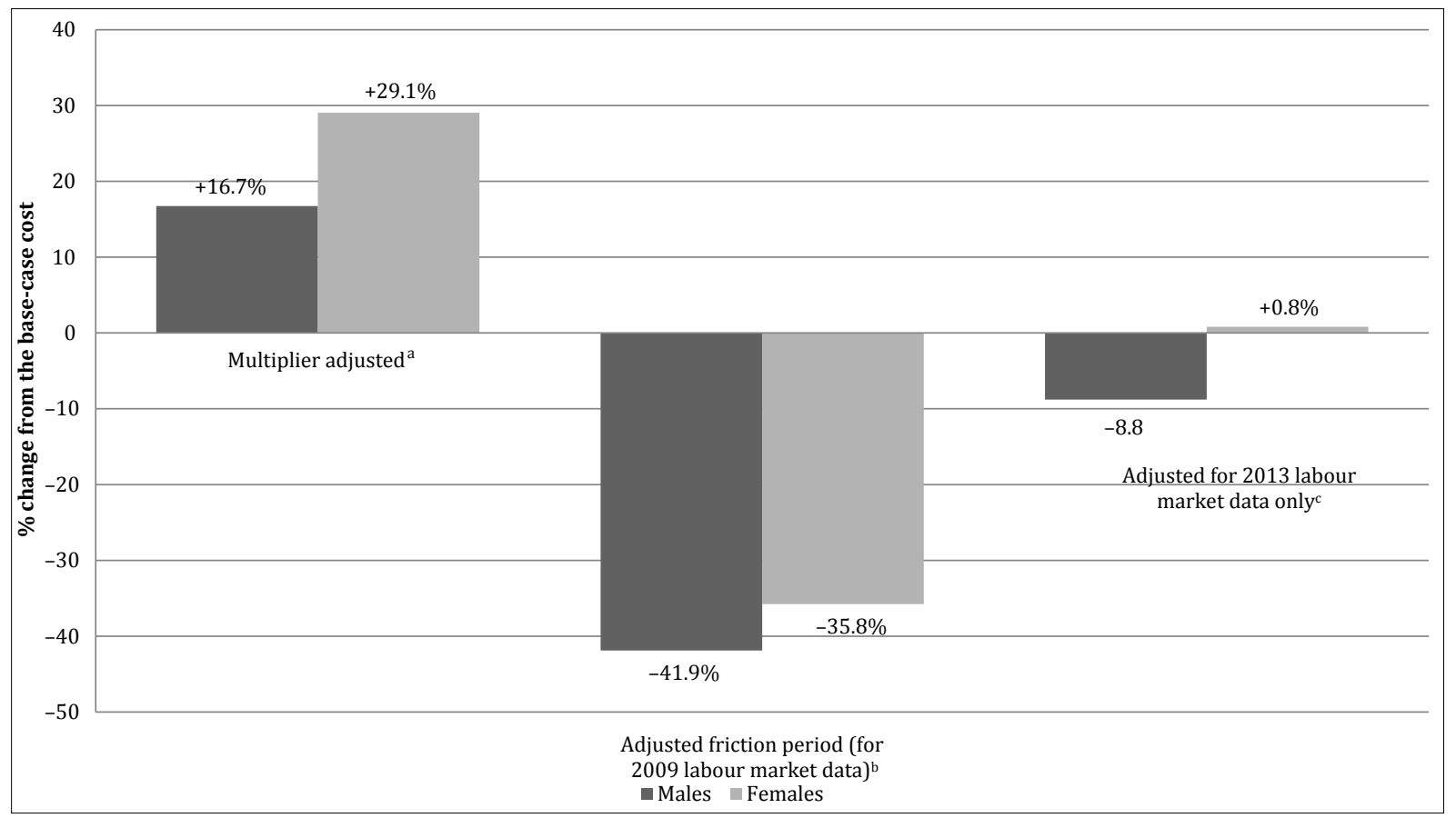

a Median multiplier estimate of 1.28 applied to base-case estimates

${ }^{b}$ Revised friction period for 2009 of 7.2 weeks applied to base-case estimates

'Base-case friction period of 11.3 weeks and 2013 unemployment and labour force participation rates applied to base-case estimates 


\section{DISCUSSION}

\section{An employer's perspective on the cost of cancer-related premature mortality}

Cancer, and indeed any serious illness, can degrade the quality and reduce the quantity of labour available, and this can have both broad macroeconomic implications in terms of reduced GDP growth (Bloom et al., 2011; MayerFoulkes, 2011; Swift, 2011) and firm-level effects including, among other things, productivity loss (Hanly et al., 2012; Nicholson et al., 2006; Oliva et al., 2005). Employers are becoming increasingly aware of adverse illness-related effects which may include a loss of critical skills obtained through years of on-the-job experience, higher employee turnover, and the need to promote employees prematurely to replace more experienced workers (Berger et al., 2001; Bloom et al., 2011; Hytter, 2007).

In this study, we used the FCA conceptual framework to estimate the magnitude of productivity costs incurred due to cancer-related premature mortality. From an employer's perspective, the FCA might be considered to provide a more realistic valuation of productivity costs pertaining to firm mortality-related turnover than the rival economic costing framework, the HCA, and thus be more informative for managerial decision making. The total all cancer premature mortality cost in Ireland in 2009 was estimated at $€ 14.3$ million. A previous study of Irish cancer-related premature mortality costs using similar data sources but applying the HCA estimated a total productivity cost of $€ 509.5$ million for 2009 (Hanly and Sharp, 2014). Controversy remains around the correct economic method for measuring and valuing productivity costs (Knies et al., 2010; Krol et al., 2013). In the relatively few available studies, it has consistently been shown that the FCA results in losses, which are substantially lower than those generated using the HCA (Goeree et al., 1999; Hanly et al., 2012; Hutubessy et al., 1999). For example, in studies in Ireland and Spain which considered specific cancers, FCA estimates for cancer-related productivity losses were approximately $1.2 \%-2 \%$ of HCA estimates (Hanly et al., 2012; Oliva et al., 2005); the comparison of the all cancer figure derived in the current study with the all cancer HCA estimate previously reported (Hanly and Sharp, 2014) is broadly consistent with these ratios. The difference arises as the HCA measures potential output loss while the FCA measures actual output lost, which means that the HCA losses accrue over a lifetime (or, at least until the usual retirement age) while those for the FCA are truncated at the end of the friction period when output is assumed restored.

The traditional employee turnover cost literature which applies accounting costing procedures decomposes the cost of turnover into three direct cost components: separation costs, replacement costs and training costs, and an indirect component of reduced productivity (Cascio, 1991; Pinkovitz et al., 1997; Tziner and Birati, 1996). The indirect component tends to concentrate on the cost of the reduced productivity of the new worker until they have reached the level of the previous employee, rather than the lost productivity cost over the entire 'friction period' (Cascio, 1991). Consequently, this represents a partial measure of productivity loss. The FCA purports to capture a more comprehensive measure of the lost productivity component and therefore provides a more meaningful measure of lost productivity compared to traditional turnover frameworks. Nevertheless, the FCA only measures one of the three direct costs outlined in the traditional accounting framework, and even then only indirectly. For example, the FCA estimates training costs as the time, and therefore lost productivity, necessary for the new hire to restore the original output level. It fails to incorporate the direct costs of training which can include those associated with the dissemination of firm information on organisational regulations, norms of conduct and core organisational values, in addition to setting up training programs and on-the-job training activities. Separation and replacement costs are similarly overlooked. This lack of recognition of direct costs associated with turnover remains a weakness of the FCA, if it claims to truly represent an employer's perspective.

Additional turnover costing approaches in the literature have highlighted the importance of other potential consequences, which may result from involuntary employee turnover, such as a fall in morale of remaining staff (and associated lost productivity), customer loss due to failure to supply services or products on schedule and the cost of maintaining a 'bench' (Curtis and Wright, 2001; Karsan, 2007; Tziner and Birati, 1996). These consequences can lead to further costs from an employer's perspective. Although they have not all been incorporated within the FCA, consideration of these types of issues led to the development of the concept of 'multiplier effects' (Krol et al., 2012; Nicholson et al., 2006; Pauly et al., 2002).

Multiplier effects incorporate the additional effects of turnover on team-based work, time-sensitive demand and where perfect substitute workers are hard to find. Sectors where vacancies are 'difficult-to-fill' in Ireland include ICT, high-tech manufacturing, agri-food, financial services and healthcare (FAS, 2013) and therefore we would expect 
the actual productivity losses in these sectors during the friction period to be higher than average. In our sensitivity analysis we applied a multiplier (1.28) derived from US-based firms (Nicholson et al., 2006) to account for these additional turnover costs. This increased Irish cancer-related premature mortality costs by $17 \%$ (to $€ 11.6$ million) for males and by $29 \%$ (to $€ 5.6$ million) for females. We suggest that these figures are perhaps more indicative of the true indirect employer costs associated with cancer-related premature mortality, but advise some caution in interpretation because of the source (i.e. US) of the multiplier estimate; an estimate for Ireland is not (as far as we are aware) available.

\section{Productivity cost estimation in practice: variation in premature mortality productivity costs by sex and age}

We found that the all cancer total premature mortality cost for males in Ireland was 2.3 times higher than that for females and a similar difference was observed in the cost per cancer death. This was despite the fact that average number of deaths from cancer in people aged 15-64 was similar in males and females $(1,145$ and 1,108, respectively). This pattern is consistent with findings from the studies of premature cancer-related mortality costs using both the FCA and the HCA conducted in other countries (Hanly et al., 2014).

The higher premature mortality cost for males than females is largely a result of gender differences in labour market factors, which are incorporated in the calculations, including wages and workforce participation rates; both of these are substantially higher in males than females. For example, among workers in Ireland aged 40-49, the average male wage was $€ 55,800$ per annum compared to $€ 37,140$ for females (Statbank, 2014b). This wage gap is a function of many factors, including the higher average number of hours worked per week by men than women (39.4 vs. 30.6), men's greater average years of work experience and the fact that more men than women have supervisory positions (CSO, 2011; ESRI, 2003). In addition, in the $45-49$ age group, for example, $88 \%$ of males participated in the workforce compared to $68 \%$ of females (Statbank, 2014a).

We also observed a trend of rising total all cancer premature mortality costs with increasing age, at least until age 60. This is due to the fact that average wages rise with age until 60 (Statbank, 2014b) and because the number of deaths increases with age for most cancers. This age-specific pattern has also been observed in studies in other countries (Hanly et al., 2015), but what was particularly striking in this study was the fact that the male:female ratio increased substantially with age. Again this reflects male-female differentials in workforce participation and wages rates, which tend to increase with age. For example, while the average male wage in the $25-29$ age group in 2009 was $12 \%$ higher than the average female wage, it is $63 \%$ higher in the 50-59 age group.

From an employer's perspective, the implication of these higher costs in males is that the productivity costs associated with the losses of male employees due to cancer-related premature mortality exceed those for female employees. This clearly has implications in terms of equity, and these need to be borne in mind when developing policies (either at the individual employer or the society level) to maximise workforce participation among people with cancer. The equity implications of using economic approaches to estimate productivity costs have been previously discussed by Williams (1992) and more recently by Krol et al. (2013).

\section{Modelling employer productivity costs during a recession}

The FCA and the related concept of the 'friction period' are closely linked to the extant labour market conditions in the economy (Koopmanschap et al., 1995). Specifically, an inverse relationship exists between the vacancy period of a job and the unemployment rate: the higher the unemployment level, the shorter the vacancy period, and thus the friction period. In sensitivity analyses, we attempted to model the effect of large increases in unemployment levels in Ireland over time on premature mortality costs. Interestingly, the greatest impact on costs was due to the change in the length of time for a firm to replace a worker, that is, the friction period; using a 7.2-week friction period instead of 11.3 weeks due to a $8.1 \%$ rise in unemployment from 2006 (base-case friction period year) to 2009 resulted in $42 \%$ lower all-cancer costs for males and $36 \%$ lower costs for females. The impact of changes in participation and unemployment rates on costs (with the friction period held constant) was minimal. The implication of this is that productivity cost estimates should be updated as economic conditions change over time, especially if the friction period is considered to have changed. This is rarely undertaken using accounting-based frameworks and represents a distinct strength of the FCA framework. 


\section{Different perspectives on the cancer burden}

The traditional measures of the cancer burden (or, indeed any other non-infectious disease) - namely numbers and rates of new cases and deaths in a specific country or defined population - take an entirely public health view. However, cancer (or any other disease) also has an economic impact which can be quantified according to the perspective of the individuals (or families) affected, society, or - as illustrated in this study - employers. In recognition of these distinct economic implications of cancer, in 2009, the Commission of the European Communities (2009) called for comprehensive and standardised information on the costs of cancer (as well as other measures of the cancer burden) to facilitate benchmarking and priority setting in relation to cancer control activities. As we have noted elsewhere (Hanly et al., 2014), the currently available literature on premature cancer-related mortality costs has significant gaps and limitations; this is particularly true with regard to costs from the employer's perspective. Studies such as this one are therefore important in expanding the scope of the evidence base on the costs of cancer.

The availability of both public health and economic measures of the cancer burden enables comparison between these different, yet complementary, perspectives and offers some interesting findings. For example, cancer of the prostate is the most commonly diagnosed cancer in men in Ireland and the third most common form of cancerrelated death (NCRI, 2013c). The average age at diagnosis is relatively old (68 years, NCRI, 2013a) and prognosis is good (5-year survival relative to the general population, $86 \%, \mathrm{NCRI}, 2013 \mathrm{c}$ ). This means that only $40 \%$ of prostate cancer deaths occur in men aged under 65 (NCRI, 2013b). Consequently, prostate cancer ranked only $8^{\text {th }}$ in terms of premature mortality costs in this study, considerably lower than when viewed from a public health perspective. In contrast, cancers of the brain and CNS rank somewhat higher when premature mortality costs, rather than mortality or incidence, are considered. This cancer ranked $3^{\text {rd }}$ in males and $6^{\text {th }}$ in females in terms of total costs, but $8^{\text {th }}$ and $9^{\text {th }}$ in terms of deaths and $13^{\text {th }}$ (for males and females separately) in terms of new cases (NCRI, 2013a). This is primarily a consequence of the relatively low age at onset $($ mean $=60)$ and poor survival $(5$-year relative survival less than 20\%; NCRI, 2013a).

\section{Economic evaluation guidelines and productivity costs}

Undertaking an economic evaluation of any health technology requires setting a perspective from which costs (and benefits) are measured. Traditionally national pharmacoeconomic guidelines have stipulated a health-payer perspective which entails the inclusion solely of direct costs that are incurred by the health provider, but there has been a move away from this in recent years (Knies et al., 2010). It has been argued that alternate perspectives including those of the employer and society - are particularly important when the results of evaluations are aimed at informing resource allocation decisions (Jonsson, 2009). Importantly, in terms of this study, adopting a societal or employer perspective generally involves the inclusion of productivity costs, commonly defined as 'costs associated with working time lost and replacement costs due to illness, disability and death of productive persons, both paid and unpaid' (Brouwer et al., 1997).

Currently, almost three quarters of national pharmacoeconomic guidelines from Europe and North America advocate the use of a societal and/or employer perspective (Knies et al., 2010). In Ireland, the recently updated national guidelines for the economic evaluation of health technologies recommend the adoption of the publicly funded health and social care system in Ireland (i.e. the Health Service Executive (HSE)) as the reference case perspective (Health Information and Quality Authority HIQA, 2014). While the guidelines further note that, if the inclusion of wider societal costs is expected to affect the results of the evaluation significantly, then a societal perspective analysis should be undertaken, they recommend that this should be presented as a supplementary analysis, separate from the reference case (HIQA, 2014). This potentially leaves Ireland at a disadvantage internationally as inconsistency in the implementation of economic evaluations makes transferability of results across jurisdictions difficult (Knies et al., 2010). Results such as those presented here highlight the importance of economic costs over and above those related solely to the health system and emphasise that additional sections of society, such as employers, are also affected by illness.

\section{LIMITATIONS AND FUTURE RESEARCH}

From a conceptual viewpoint, the FCA provides a valuable framework for the measurement of the indirect costs of premature mortality-related turnover from an employer perspective. However, in its current state, this framework lacks a comprehensive measure of direct turnover costs. Further research in this area could concentrate on 
combining elements of direct turnover cost (perhaps estimated according to accounting costing frameworks) with the indirect costs measured by the economic costing framework of the FCA. In so doing, additional costs would be recognised and quantified including effects on staff morale of turnover due to premature mortality and the effects of grief on staff. Grief, in particular, has to date remained a hidden cost but the financial and productivity effects are potentially large (Hazen, 2008, 2009; James and Friedman, 2003). These costs can accrue due to difficulty in concentration and errors in judgment, injuries and accidents (James and Friedman, 2003). Apportioning a monetary value to these effects would enhance measures purporting to value productivity costs.

Productivity costs related to illness can arise due to a number of distinct time losses of which premature mortality is only one. For example, although cancer treatment often results in full recovery, some survivors experience ongoing side effects which can impact on their cognitive and physical functioning at work (Grunfeld et al., 2008; Spelten et al., 2002), and hence productivity. Additional productivity costs can include temporary and permanent absenteeism, and return to work with reduced hours and/or reduced productivity in the workplace (presenteeism) (Zhang et al., 2011). Relatively, little attention has been paid to these types of cancer-related costs, particularly from an employer perspective. This suggests that further research might concentrate on estimating a broader range of cancer productivity costs. The limited extant literature has estimated that temporary and non-mortality-related permanent work absences can account for a considerable proportion of the total productivity costs associated with colorectal, prostate and breast cancer (Hanly et al., 2012, 2013), but the absolute and relative magnitude of the costs vary by cancer type. Therefore, further research is required to measure these additional costs across a range of cancer sites, particularly given improving cancer survival rates and rising retirement ages which mean that the number of working-age cancer survivors will continue to rise.

The application of the FCA enabled the valuation of costs from an employer's perspective. However, this approach requires an estimate of the 'friction period' which we derived, in the base-case, from a CSO (2009) survey undertaken in 2006. This survey was a one-off piece of research, and, as our results demonstrate, the FCA estimates are rather sensitive to the assumed length of the friction period. Although we estimated changes in this friction period due to rising unemployment using results published in the literature, the collection of stock and flow data on new vacancies in the labour market would greatly enhance this process for future studies of cancer and other conditions.

As noted earlier, our estimate of the multiplier was obtained from a US study (Krol et al., 2012); and is, to our knowledge, the only available estimate. Different settings, with distinctive labour market characteristics, are likely to require different multiplier effects. Future research could (like the US study) undertake a survey of firms in Ireland to establish multipliers specific to this economy. In addition, we used a median multiplier, that is, one averaged across a range of professions. The application of profession-specific multipliers (which are available in the US study) is likely to lead to more accurate productivity cost estimates; however, Irish wage data are not reported in sufficient detail to enable such calculations. Thus, more detailed reporting of wage data would enhance future studies (using either the FCA or HCA).

Employers, supervisors and line managers play a crucial role in supporting the successful transition by cancer survivors back into the work environment and their subsequent retention in the workforce (Amir et al., 2008; de Boer, 2014). Various specific employer-related interventions - such as employer-organised return-to-work meetings, flexible working conditions, counselling and job replacement services - have been proposed to support this transition (Mehnert et al., 2013) and various vocational rehabilitation programmes have been introduced in the UK and elsewhere. However, these strategies have not yet been widely implemented and their effectiveness in terms of increasing return to work, and/or a return to full productivity at work - and, importantly, their cost-effectiveness remain poorly understood. Further research is required (including in an Irish setting) on the role that employers can play in promoting successful return to work and ongoing retention in the workforce.

\section{CONCLUSION}

Employers are becoming increasingly aware of the adverse effects of illness on workplace productivity. Cancer, and specifically cancer-related mortality, imposes considerable economic costs on the employer in addition to the obvious huge personal loss to family and friends. Our study aimed to measure cancer-related premature mortality costs in Ireland using a methodological framework rarely applied in the management literature. The estimated results provide a sense of the types and magnitude of indirect costs which are currently excluded from existing 
accounting methods of estimating the lost productivity of involuntary turnover. Specifically, the all-cancer premature mortality cost for Ireland was valued at $€ 14.3$ million in 2009 from an employer's perspective. This estimate is derived from the application of a conceptualisation of involuntary turnover costs which concentrates on the indirect costs of involuntary turnover rather than the direct costs such as setting up training programs and on-thejob training activities. The estimate also accounts for 'multiplier effects' which incorporate the additional effects of turnover on team-based work, time-sensitive demand and difficulty in finding perfect substitutes and therefore captures additional costs compared to most previous applications of the FCA. Nevertheless, the methodological framework applied is incomplete and future research should attempt to combine elements of direct turnover cost according to accounting costing frameworks with the indirect costs measured by the FCA to derive a holistic measure of productivity costs associated with an illness like cancer. This should entail, among other things, the recognition and quantification of productivity costs due to the effects of grief on workplace morale.

\section{ACKNOWLEDGEMENTS}

We appreciate the support of COST Action IS1211 CANWON.

\section{References}

Amir, Z., Neary, D. and Luker, K. (2008). 'Cancer survivors' views of work 3 years post diagnosis: a UK perspective'. European Journal of Oncology Nursing, 12: 3, 190-197.

Berger, M.L., Murray, J.F., Xu, J. and Pauly, M. (2001). 'Alternative valuations of work loss and productivity'. Journal of Occupational and Environmental Medicine, 43: 1, 18-24.

Bloom, D.E., Cafiero, E.T., Jané-Llopis, E., AbrahamsGessel S. and Bloom, L.R. (2011). The global economic burden of noncommunicable diseases. http://www3.weforum.org/docs/ WEF_Harvard_HE_GlobalEconomicBurdenNonCommunicableDiseases_2011.pdf [Accessed 23 February 2013].

Bradley, C.J., Oberst, K. and Schenk, M. (2006). 'Absenteeism from work: The experience of employed breast and prostate cancer patients in the months following diagnosis'. Psychooncology,15: 8, 739-747.

Bradley, C.J., Yabroff, K.R., Dahman, B., Feuer, E.J., Mariotto, A. and Brown, M.L. (2008). 'Productivity costs of cancer mortality in the United States: 2000-2020'. Journal of the National Cancer Institute, 100: 24, 1763-1770.

Brouwer, W.B.F., Koopmanschap, M.A. and Rutten, F.F.H. (1997). 'Productivity costs measurements through quality of life? A response to the recommendations of the Washington Panel'. Health Economics, 6: 3, 253-259.

Campion, M.A. (1991). 'Meaning and measurement of turnover: Comparison of alternative measures and recommendations for research'. Journal of Applied Psychology, 76: 2, 199-212.
Cascio, F.W. (1991). Managing Human Resources: Productivity, Quality of Work Life and Profits, NY: McGraw Hill.

Central Statistics Office (CSO). (2009). Employee skills, training and job vacancies survey 2006. http:// www.cso.ie/en/media/csoie/releasespublications/ documents/earnings/current/empskills.pdf [Accessed 14 October 2013].

Central Statistics Office (CSO). (2011). Men leave school earlier and women are more highly qualified, http://www.cso.ie/en/newsandevents/ pressreleases/2012pressreleases/pressreleasewomenandmeninireland2011 [Accessed 10 May 2014].

Commission of the European Communities. (2009). Communication from the Commission to the European Parliament, the Council, the European Economic and Social Committee and the Committee of the Regions on Action Against Cancer: European Partnership' 291, 1-10. http://eurlex.europa.eu/ legalcontent/EN/TXT/?uri=URISERV:sp0011.

Curtis, S. and Wright, D. (2001). 'Retaining employees - The fast track to commitment'. Management Research News, 24: 8, 59-64.

de Boer, A.G. (2014). 'The European cancer and work network: CANWON'. Journal of Occupational Rehabilitation, 24: 1, 393-398.

Drummond, M.F. (1992). 'Cost-of-illness studies: A major headache'. Pharmacoeconomics, 2: 1, 1-4.

Drummond, M., Barbieri, M., Cook, J., Glick, H., Lis, J., Malik, F. and Severens, J. (2009). 'Transferability of economic evaluations across jurisdictions: ISPOR good research practices task force report'. Value in Health, 12: 4, 409-418. 
Erdogan-Ciftci, E. and Koopmanschap, M.A. (2011). 'Estimation of productivity costs using the friction cost method: New evidence using national data'. Value in Health, 14: 7, 235-236.

ESRI. (2003). The gender wage gap in Ireland: Evidence from the National Employment Survey 2003. http://www.equality.ie/Files/ The $\% 20$ Gender $\% 20$ Wage $\% 20$ Gap $\% 20$ in $\% 20$ Ireland.pdf [Accessed 9 May 2014].

FÁS. (2013). National Skills Bulletin 2013. http://www.fas.ie/NR/rdonlyres/9734B491956D-4E4B-8326-6EF1C11E7C2E/3280/ NationalSkillsBulletinJuly2013.pdf [Accessed 5 May 2014].

Goeree, R., O’Brien, B.J., Blackhouse, G., et al. (1999). 'The valuation of productivity costs due to premature mortality: A comparison of the human-capital and friction-cost methods for schizophrenia'. Canadian Journal of Psychiatry, 44, 455-463.

Grunfeld, E.A., Rixon, L., Eaton, E. and Cooper, A.F. (2008). 'The organisational perspective on the return to work of employees following treatment for cancer'. Journal of Occupational Rehabilitation, 18: 4, 381-388.

Hanly, P., Pearce, A. and Sharp, L. (2014). 'The cost of premature cancer-related mortality: A review and assessment of the evidence'. Expert Review of Pharmacoeconomics and Outcomes Research, 14: 1, 355-377.

Hanly, P. and Sharp, L. (2014). 'The cost of lost productivity due to premature cancer-related mortality: An economic measure of the cancer burden'. BMC Cancer, 14: 1, 224.

Hanly, P., Soerjomataram, I. and Sharp, L. (2015). 'Measuring the societal burden of cancer: The cost of lost productivity due to premature cancerrelated mortality in Europe'. International Journal of Cancer, 136: 4, 136-145.

Hanly, P., Timmons, A., Walsh, P.M. and Sharp, L. (2012). 'Breast and prostate cancer productivity costs: A comparison of the human capital approach and the friction cost approach'. Value in Health, 15: 3, 429-436.

Hanly, P., Walsh, P.M., O'Ceilleachair, A., Skally, M., Staines, A., Kapur, K., Fitzpatrick, P. and Sharp, L. (2013). 'Work-related productivity losses in an era of ageing populations: The case of colorectal cancer'. Journal of Occupational and Environmental Medicine, 55: 2, 128-134.

Hazen, M.A. (2008). 'Grief and the workplace'. The Academy of Management Perspectives, 22: 3, 7886.
Hazen, M.A. (2009). 'Recognizing and responding to workplace grief'. Organizational Dynamics, 38: 4, 290-296.

Health Information and Quality Authority (HIQA). (2014). Guidelines for the economic evaluation of health technologies in Ireland. http://www.hiqa. ie/publications/guidelineseconomic-evaluationhealth-technologies-ireland $>\backslash$ [Accessed 15 April 2014].

Hutubessy, R.C., van Tulder, M.W., Vondeling, H. and Bouter, L.M. (1999). 'Indirect costs of back pain in the Netherlands: A comparison of the human capital method with the friction cost method'. Pain, 80: 1, 201-207.

Hytter, A. (2007). 'Retention strategies in France and Sweden'. Irish Journal of Management, 28: 1, 5979.

James, J.W. and Friedman, R. (2003). Grief Index: The 'Hidden' Annual Costs of Grief in America's Workplace. The Grief Recovery Institute Educational Foundation, Inc. http://www.griefrecovery.com/request_index.htm [Accessed 15 August 2014].

Jonsson, B. (2009). 'Ten arguments for a societal perspective in the economic evaluation of medical innovations'. European Journal of Health Economics, 10: 4, 357-359.

Karsan, R. (2007). 'Calculating the cost of turnover'. Employment Relations Today, 34: 1, 33-36.

Knies, S., Severens, J.L., Ament, A.J. and Evers, S.M. (2010). 'The transferability of valuing lost productivity across jurisdictions. Differences between national pharmacoeconomic guidelines'. Value Health, 13: 5, 519-527.

Koopmanschap, M. and Rutten, F. (1996). 'A practical guide for calculating indirect costs of disease'. Pharmacoeconomics, 10: 5, 460-466.

Koopmanschap, M.A., Rutten, F.F., van Ineveld, B.M. and van Roijen, L. (1995). 'The friction cost method for measuring indirect costs of disease'. Journal of Health Economics, 14: 2, 171-189.

Krol, M., Brouwer, W. and Rutten, F. (2013). 'Productivity costs in economic evaluations: Past, present, future'. Pharmacoeconomics, 31: 7, 537-549

Krol, M., Brouwer, W.B., Severens, J.L., Kaper, J. and Evers, S. (2012). 'Productivity cost calculations in health economic evaluations: Correcting for compensation mechanisms and multiplier effects'. Social Science and Medicine, 75: 11, 1981-1988.

Lee, T.W. and Mitchell, R.R. (1994). 'An alternative approach: The unfolding model of voluntary employee turnover'. Academy of Management Review, 19: 1, 51-89. 
March, J.G. and Simon, H.A. (1958). Organizations, NY: Wiley.

Mayer-Foulkes, D. (2011). 'A survey of macro damages from non-communicable chronic diseases: Another challenge for global governance'. Global Economy Journal, 11: 1, 6.

Mehnert, A. (2011). 'Employment and work-related issues in cancer survivors'. Critical Reviews in Oncology and Haematology, 77: 2, 109-130.

Mehnert, A., de Boer, A. and Feuerstein, M. (2013). 'Employment challenges for cancer survivors'. Cancer, 119: S11, 2151-2159.

Mobley, W.H. (1977). 'Intermediate linkages in the relationship between job satisfaction and employee turnover'. Journal of Applied Psychology, 62: 2, 237-240.

Mobley, W.H., Griffeth, R.W., Hand, H.H. and Meglino, B.M. (1979). 'Review and conceptual analysis of the employee turnover process'. Psychological Bulletin, 86: 3, 493-522.

Mobley, W.H., Horner, S.D. and Hollingsworth, A.T. (1978). 'An evaluation of precursors of hospital employee turnover'. Journal of Applied Psychology, 63: 4, 408-414.

Mushkin, S.J. (1962). 'Health as an investment'. Journal of Political Economy, Supplementary Issue, 129157.

National Cancer Registry Ireland (NCRI). (2013a). Cancer in Ireland 2013: Annual Report of the National Cancer Registry. http://www.ncri.ie/ publications/statistical-reports/cancer-ireland2013-annual-report-national-cancer-registry [Accessed 10 January 2014].

National Cancer Registry Ireland (NCRI). (2013b). Cancer Factsheet: Prostate. http://www.ncri.ie/ sites/ncri/files/factsheets/FACTSHEET_prostate. pdf [Accessed 12 May 2014].

National Cancer Registry Ireland (NCRI). (2013c). Cancer Factsheet: Female breast. http://www. ncri.ie/sites/ncri/files/factsheets/FACTSHEET_ female\%20breast.pdf [Accessed 12 May 2014].

Nicholson, S., Pauly, M.V., Polsky, D., Sharda, C., Szrek, H. and Berger, M.L. (2006). 'Measuring the effects of work loss on productivity with team production'. Health Economics, 15: 2, 111-123.

OECD. (2013). Statistics on average effective age and official age of retirement in OECD countries. http:// www.oecd.org/els/public-pensions/ageingandemploymentpoliciesstatisticsonaverageeffectiveageofretirement.html [Accessed 5 February 2014].

Oliva, J., Lobo, F. and Lopez-Bastida, J. (2005). 'Indirect costs of cervical and breast cancers in Spain'. European Journal of Health Economics, 6: 4, 309-
313.

Pauly, M.V., Nicholson, S., Xu, J., et al. (2002). 'A new general model of the impact of absenteeism on employers and employees'. Health Economics, 11: 3, 221-231.

Pinkovitz, W.H., Moskal, J. and Green, G. (1997). 'How much does your employee turnover cost'. Small Business Forum, 14: 3, 70-71.

Price, J.L. (1977). The Study of Turnover, Ames, IA: lowa State University Press.

Rice, D.P. (1966). 'Estimating the cost of illness'. Health Economics Series, 6. DHEW pub no (PHS). Washington, DC, 947-6.

Rice, D.P. (1967). 'Estimating the cost of illness'. American Journal of Public Health and the Nation's Health, 57: 3, 424-440.

Sharp, L. and Timmons, A. (2011). 'Social welfare and legal constraints associated with work among breast and prostate cancer survivors: Experiences from Ireland'. Journal of Cancer Survivorship, 5: 4, 382-394.

Spelten, E.R., Sprangers, M.A. and Verbeek, J.H. (2002). 'Factors reported to influence the return to work of cancer survivors: A literature review'. Psychooncology, 11: 2, 124-131.

Statbank. (2014a). http://www.cso.ie/px/pxeirestat/ Database/eirestat/National\%20Employment $\% 20$ Survey/National $\% 20$ Employment $\% 20$ Survey_statbank.asp? SP = National EmploymentSurvey\&Planguage $=0$ [Accessed 6 February 2014].

Statbank. (2014b). http://www.cso.ie/px/pxeirestat/ Database/eirestat/Quarterly\%20National\%20 Household\%20Survey\%20Main\%20Results/ Quarterly\%20National\%20Household $\% 20$ Survey $\% 20$ Main $\% 20$ Results_statbank. asp?SP=Quarterly NationalHousehold Survey Main Results\&Planguage $=0$ [Accessed 6 February 2014].

Steel, R.P. (2002). 'Turnover theory at the empirical interface: Problems of fit and function'. Academy of Management Review, 27: 3, 346-360.

Steel, R.P. and Lounsbury, J.W. (2009). 'Turnover process models: Review and synthesis of a conceptual literature'. Human Resource Management Review, 19: 4, 271-282.

Swift, R. (2011). 'The relationship between health and GDP in OECD countries in the very long run'. Health Economics, 20: 3, 306-322.

Tan, S., Bouwmans, C., Rutten, F. and Hakkaart-van Roijen, L. (2012). 'Update of the Dutch manual for costing in economic evaluations'. International Journal of Technology Assessment in Health Care, 28: 2, 152-158. 
Tarricone, R. (2006). 'Cost-of-illness analysis. What room in health economics?'. Health Policy, 77: 1, 51-63.

Tziner, A. and Birati, A. (1996). 'Assessing employee turnover costs: A revised approach'. Human Resource Management Review, 6: 2, 113-122.

Williams, A. (1992). 'Cost-effectiveness analysis: Is it ethical?' Journal of Medical Ethics, 18: 1, 7-11.

World Health Organization (WHO). (2013). Mortality database. http://www-dep.iarc.fr/WHOdb/WHOdb. htm [Accessed 4 March 2013].
World Health Organisation (WHO). (2008). Global health observatory data repository. Cause-specific mortality, 2008. http://apps.who.int/gho/data/node. main.887 [Accessed 22 January 2014].

Zhang, W., Bansback, N. and Anis, A.H. (2011). 'Measuring and valuing productivity loss due to poor health: A critical review'. Social Science and Medicine, 72: 2, 185-192. 